\title{
Social Media Use for Crisis and Emergency Risk Communications During the Zika Health Crisis
}

\author{
LONI HAGEN and STEPHEN NEELY, University of South Florida, Tampa, FL \\ RYAN SCHARF, American Integrity Insurance, Tampa, FL \\ THOMAS E. KELLER, University of South Florida, Tampa, FL
}

\begin{abstract}
Many public officials and government agencies are facing increased pressure to utilize social media as a crisis communications tool. However, significant questions remain unanswered regarding how social media can be best leveraged to facilitate effective communication efforts under crisis conditions. These questions are often more challenging for local government agencies, where unsupportive culture and a lack of resources tend to discourage the active use of social media in governing. In an effort to better inform these discussions, this article examines the use of Twitter by federal, state, and local government actors during the 2015-2016 Zika virus outbreak in the United States. The findings show that local governments have smaller network sizes, on average, than their state and federal counterparts. In contrast, federal-level agencies tend to enjoy larger network sizes, which they frequently leverage as a tool for disseminating information. Elected office holders, in general, managed large networks and leveraged their popularity during the crisis. This analysis offers insight for both scholars and practitioners in the areas of emergency management and public administration, as it helps to deepen our understanding of how government agencies and political leaders across various levels of government engage with the public during times of crisis.
\end{abstract}

CCS Concepts: • Social and professional topics; • Applied computing; $\rightarrow$ Computers in other domains; Computing in government; E-government;

Additional Key Words and Phrases: Social media, e-government, crisis and emergency risk communications, emergency management, local government, Twitter

ACM Reference format:

Loni Hagen, Stephen Neely, Ryan Scharf, and Thomas E. Keller. 2020. Social Media Use for Crisis and Emergency Risk Communications During the Zika Health Crisis. Digit. Gov.: Res. Pract. 1, 2, Article 13 (April 2020), 21 pages.

https://doi.org/10.1145/3372021

\section{INTRODUCTION}

As social media platforms have grown in popularity over recent years, they have increasingly become a primary source of news and information for large segments of the American public. The Pew Research Center, which has tracked social media usage since 2005, reports that more than two-thirds of all Americans now receive at least some portion of their news via social media [50]. These tendencies have been pronounced in times of crisis,

Loni Hagen was supported by the National Research Foundation of Korea funded by the Korean Government (NRF-2017S1A3A2066084). Authors' addresses: L. Hagen; email: lonihagen@usf.edu; S. Neely; email: srneely@usf.edu; R. Scharf; email: ryan.scharf@gmail.com; T. E. Keller; email: tekeller@usf.edu.

Permission to make digital or hard copies of all or part of this work for personal or classroom use is granted without fee provided that copies are not made or distributed for profit or commercial advantage and that copies bear this notice and the full citation on the first page. Copyrights for components of this work owned by others than ACM must be honored. Abstracting with credit is permitted. To copy otherwise, or republish, to post on servers or to redistribute to lists, requires prior specific permission and/or a fee. Request permissions from permissions@acm.org.

(c) 2020 Association for Computing Machinery.

2639-0175/2020/04-ART13 $\$ 15.00$

https://doi.org/10.1145/3372021

Digital Government: Research and Practice, Vol. 1, No. 2, Article 13. Publication date: April 2020. 
with social media usage often surging during public emergencies as citizens seek out critical information such as damage, weather, and traffic updates [1, 48, 59]. As an example, [25] note that more than 20 million storm-related posts were sent via Twitter in the days immediately surrounding Hurricane Sandy, with more than half of them including news, information updates, and storm-related videos.

As Americans become more reliant on social media for emergency information, public officials and government agencies are increasingly utilizing these technologies to communicate with the citizenry during times of crisis $[11,44]$. Public expectations have also increased, resulting in heighted pressure on government agencies to more efficiently and comprehensively integrate social media into their crisis communication strategies. A study conducted by the American Red Cross in 2012 found that over two-thirds of Americans believe emergency responders should actively participate in social media, while nearly three-quarters indicated that they would anticipate timely responses from emergency personnel when posting requests for assistance on social media [1]. Proponents of social media generally support greater engagement on the part of political officials and public agencies, arguing that these platforms can increase the speed and alacrity with which emergency information is distributed, expand public access to information in times of crisis, and engage private citizens in the emergency response process by allowing them to both create and redistribute crisis-related information [22, 29].

The use of social media by political actors has been highly visible over recent years, and the strategic value of these technologies for politics and electioneering has been well documented (i.e., [30]). However, over the same time, significant questions have been raised over the manner in which public agencies themselves might most effectively communicate via social media, as well as the factors that drive varying rates of adoption by agencies at different levels of government. Although the digital footprints of many government agencies have expanded, data show that these organizations still lag notably behind their private-sector counterparts in social media adoption [15, 20]. This has been particularly true of smaller, local governments, which are considerably less likely to utilize social media than state and federal agencies [20,46]. Additionally, it has been widely suggested that public agencies typically underutilize social media by focusing on limited, mono-directional communications (such as using platforms like Facebook and Twitter to push information out to citizens) rather than engaging the public in collaborative, multidirectional communications [21, 41, 42]. In the case of emergency management and response, this could result in lost opportunities to communicate critical information to vulnerable publics.

In this study, we seek to address several of these concerns by analyzing the use of Twitter by public agencies and actors during a recent public health emergency. Focusing on the 2016 Zika outbreak in Florida, we examine the use of Twitter by public agencies and officials across three levels of government (local, state, and federal). We employ a mixed-methods approach to identify and describe differences in the quantity, scope, and content of social media posts by various actors and agencies. We believe that this analysis will be of value to both scholars and practitioners in the areas of emergency management, public administration, and political science, as it helps to deepen our understanding of how government agencies and public officials engage with the citizenry during times of crisis, as well as how social media usage differs across various levels of government.

\section{RELATED WORK}

\subsection{The Growth of Social Media in the Public Sphere}

In 2005, the Pew Research Center reported that 7\% of American adults were active on social media [54]. Little more than a decade later, as many as $79 \%$ of online Americans utilized Facebook alone ${ }^{1}$ [24]. While social media use has become ubiquitous among younger, more educated individuals, the exponential growth in adoption has been driven in no small part by substantial increases in participation among those classified as "nontraditional users," including senior citizens, ethnic minorities, rural residents, and individuals from low-income households $[39,54]$. This rapid expansion of social media usage has revolutionized public communications and information seeking in the United States. In a more recent study by the Pew Research Center, [50] show that more than

\footnotetext{
${ }^{1}$ According to the same Pew study [24], 86\% of Americans are currently considered internet users.

Digital Government: Research and Practice, Vol. 1, No. 2, Article 13. Publication date: April 2020.
} 
two-thirds of Americans now access at least some news through social media, and evidence suggests particularly high levels of online information seeking in areas such as politics, public health, and emergency readiness/ response [50].

With this growth has come heightened expectations on the part of the public for both elected leaders and public agencies to be active on social media. In many regards, these expectations have posed unique challenges, as government agencies and public officials often find it difficult to keep pace with technological advancements and evolving public preferences. The adoption and usage of social media by elected officials has been highly visible over recent years, most notably in the campaigns of national candidates such as Barack Obama and Donald Trump [18, 32]. However, for governing agencies and public managers, the adoption and integration of social media has been somewhat slower and considerably more challenging, as significant questions remain regarding how best to utilize social media in public service delivery, as well as how to reconcile these rapidly emerging platforms with ongoing concerns such as open government, privacy, and intellectual property [28].

In 2009, the Obama administration issued a Memorandum on Transparency and Open Government [61], followed by an Open Government Directive [52], which called upon federal agencies to embrace "emerging technologies" in an effort to enhance transparency, collaboration, and public participation. These initiatives did prompt an acceleration in social media adoption by government agencies. Mergel [45] reports that as of 2012, "the 698 departments, agencies, and initiatives of the U.S. federal government have created 488 Facebook pages, 363 Twitter accounts, 247 YouTube channels, and 71 Flickr pages” (p. 282). Yet in spite of this progress, rates of adoption among public agencies continue to lag behind those of private-sector organizations-particularly at the local government level, where measuring participation has proven quite difficult. Estimates of social media usage by local governments have ranged from $30 \%$ to $70 \%$ in different studies [15, 21], but collectively these analyses have consistently shown that local municipalities adopt social media at significantly lower rates than their state and federal counterparts [20].

Additionally, a number of critics have suggested that public agencies underutilize social media, thereby limiting its impact on the public sphere. Karakiza [31] noted that social media differ significantly from earlier e-government applications, which only allowed for the one-way transmission of information from governing agencies to citizens. In contrast, social media allow agencies to both distribute and receive information. Engaging citizens in this collaborative way may allow for the more rapid recognition of public problems and preferences. However, a number of studies have found that public agencies tend to treat social media merely as a tool for broadcasting information rather than a multidirectional communication platform to facilitate citizen engagement [21,41], resulting in a troubling "expectations gap" between public officials and those whom they serve.

\subsection{Crisis and Emergency Risk Communications}

Traditionally, studies on emergency communications have fallen under two broad categories-crisis communication and risk communication. Crisis communication is "defined broadly as the collection, processing, and dissemination of information required to address a crisis situation" [13]. Crisis communication is typically associated with public relations efforts to "strategically manage and frame public perceptions of an event so that harm is reduced for both the organization and stakeholders" [55]. Therefore, crisis communication studies frequently investigate cases related to harm mitigations in organizational settings (such as corporate contexts) [55]. The primary concern of crisis communication is "what is known and what is not known about a specific event" [55]. For this reason, the major criticism of crisis communication as a theoretical framework is that its focus is limited to public relations efforts by individual organizations, and it fails to address strategic decision-making concerns beyond the impacted organizations [8]. Risk communication is a closely related field of study where the main focus is on the "identification of risks to the public health and efforts to persuade the public to adopt more healthy, less risky behaviors" [55]. Risk communication has been developed primarily within the health communication domain. Therefore, studies in this area are heavily dependent on health campaign cases such as 
HIV/AIDS, drunk driving, vaccines, and drug abuse [55]. The main concern of risk communication is to figure out the probabilities of some harm and to communicate methods to reduce possible harms [55]. The major limitation of risk communication is that it is limited to health-related issues and as such does not account for the urgency often associated with acute public emergencies [8].

Since major crisis events typically contain elements associated with both crisis and risk communications, the Centers for Disease Control and Prevention (CDC) has begun to employ the Crisis and Emergency Risk Communication (CERC) framework as a way of incorporating both areas of knowledge. CERC is an official term denoting "an evidence-based framework and best practices for anyone who communicates on behalf of an organization responding to a public health emergency" [8].

CERC prescribes measures to be taken based on the various stages of a crisis event-precrisis, crisis response, and postcrisis phases [55]. The precrisis stage involves preparing the public for a potential/impending crisis. This includes developing a collective understanding of the crisis event, while also educating members of the public on proper preparation. The crisis response phase involves rapid communication, particularly toward affected groups. This includes activities aimed at reducing crisis-related uncertainty. During this phase, it is important to ensure an accurate public understanding of the current/ongoing situation and risks, and to provide broad support for and cooperation with response and recovery efforts, which requires ongoing explanation and reiteration of personal response activities. The postcrisis phase focuses on recovery efforts and remediation after the crisis event. During this phase, it is important to evaluate responses and to improve future actions as they pertain to crisis communication and response capabilities.

\subsection{Use of Social Media for CERC}

As public uses of social media have expanded, the value of these tools for crisis communication has been of particular interest. In times of emergency, public officials and government agencies have a need to be "front and center" in order to communicate critical information to the citizenry. Given the increasing prevalence of social media, this means a visible presence in those social networks on which members of the public are most active. Not only does the public increasingly expect this level of engagement from public officials and agencies, but also it has been argued by a number of scholars and practitioners that social media can hasten the flow of information under crisis conditions $[29,53]$ while also reducing the workload for emergency response agencies by cutting down on the number of unique information requests received [29,33].

The potential for social media to reshape crisis communications has been evident on a number of occasions in recent years. For example, in the days immediately surrounding Hurricane Sandy, social media use swelled, as more than 20 million hurricane-related tweets were sent-more than half of them containing links to news, information, and storm-related videos [25, 59]. Public officials, such as the governors of New York and New Jersey, utilized social media extensively to communicate emergency response information to the public, and notably, social media platforms such as Twitter remained accessible even after the storm disrupted cellular service and electricity. Similarly, social media were used extensively in coordination of the FBI's ongoing law enforcement efforts following the 2013 Boston Marathon Bombing, as well as in cleanup and recovery efforts following the Deepwater Horizon Oil Spill in 2010 [44, 58].

While the use of social media has been highly visible in times of acute crisis-such as hurricanes, earthquakes, and even terrorist attacks-social networks are also transforming emergency communications in the area of public health. Over recent years, institutions and agencies such as the World Health Organization (WHO) and CDC have increasingly employed social media to communicate critical health-related information to the public [64]. These tools have also been integrated into localized public health communications, such as the dissemination of disease prevention tips and even ER wait times [44, 60]. As in the case of acute disasters, social media can accelerate the diffusion of information through dense social networks, as evidenced by the 2009 H1N1 influenza outbreak. During that crisis, the Alexandria Virginia Health Department used Twitter to effectively direct citizens to vaccination sites [44]. Similar efforts were made during the West African Ebola outbreak [19].

Digital Government: Research and Practice, Vol. 1, No. 2, Article 13. Publication date: April 2020. 


\subsection{Social Media Contents}

Our understanding of how governments use social media during public health emergencies is still evolving and requires more analysis and attention in order to better identify the official and unofficial actors naturally involved, as well as the content that is communicated by these actors. Several previous studies on the use of social media by governments have investigated the content of social media. According to a typology developed by DePaula et al. [17], the content of social media posts can be classified into four categories: (1) information provision, (2) input seeking, (3) politics, and (4) symbolic presentation.

Information provision. Multiple empirical studies on the use of social media by governments found that social media are mainly used for one-way information provision purposes [47, 51,65]. Governments frequently use social media for public reporting and public education campaigns [7, 38]. Public reporting is considered to be a fundamental duty of government officials to constantly update government decisions and actions in order to maintain an informed citizenry [3,35]. DePaula et al. [17] report that information provision can be further divided into operational/event information and public service announcements depending on the characteristics of information provided.

Input seeking. Social media also make interactive communications possible, enabling public officials and government agencies to both distribute and solicit information from the public. Social media posts often contain URLs or hashtags that refer to offline or external collaborative activities. Public officials adopt these interactive features to draw more meaningful participation from citizens and to interact with constituents. Rahm Emanuel, the mayor of Chicago, has held online townhall meetings and used Twitter to solicit ideas regarding the city's budget. Other mayors report holding regular online question-and-answer sessions [47].

Politics. A growing number of politicians use Twitter for political campaigns in order to promote their own skills, ability, or performance, or for criticizing, challenging, and contradicting other politicians, parties, or organizations in a political context [23]. Politicians also use Twitter in order to create visibility, and thus build recognition between the public and the candidates [23]. Bright et al. concluded that the "use of Twitter does make a positive difference to voting outcomes," although the size of the effect is small [5]. In contrast, a different study found that Twitter volume does not predict voting results and suggested that Twitter needs to be understood as a tool for political communication [40] rather than predicting voting results. Considering the fact that Twitter is now highly politicized, communications during health emergencies can possibly be influenced by politics. In fact, [26] found high volumes of political content in Zika-related tweets.

Symbolic presentations. Many social media posts are used to present favorable images to boost certain contents while omitting other contents for impression management or public relations purposes [17]. While many e-government scholars discuss the possible value of social media as tools for collaboration and interaction [34, 46], the study of [17] of government Facebook data, in contrast, revealed that social media are also widely adopted for self-presentation and symbolic acts. Another study found that police departments use social media to counteract negative publicity circulated by the local press [43]. Similarly, a study of European parliaments' use of social media found that $11 \%$ of the social media posts are "created purely to promote interest for the institution" [36]. Some communications take the form of symbolic presentations that result in developing shared meaning among the audience [6], shaping organizational identity [56], and sense-making [27]. DePaula et al. [17] note that symbolic acts refer to "instances of small talk, exchange of cultural references, and the use of imagery that is not explicitly political or policy related". Symbolic presentations are different from information provision because the message itself is not to provide information, but to share emotions with the audience. For example, Simon et al. found that during a terrorist attack, Twitter users often circulated tweets in order to offer "reassurances, condolences and verbal reinforcements to the public and responding organizations" [57].

This study seeks to better understand how public agencies and elected officials across varying levels of government utilize social media in times of crisis, especially during the crisis response phase. Specifically, this study 
examines federal, state, and local actors and agencies, analyzing their use of social media during the 2015-2016 Zika virus outbreak in the southeastern United States. Particular attention is paid to (1) the attributes of tweets, including the use of multimedia, and (2) the content communicated by these actors via Twitter. Comparisons are made across both types of actors and levels of government.

\section{METHODS}

\subsection{Data Collection}

Using the Twitter Streaming Application Programming Interface (API) with "Zika" as the query, we collected Twitter data from August 25, 2016, to September 21, 2016, during which reported cases of Zika increased dramatically, particularly in the Miami, Florida, area [16].

\subsection{Data Selection and Sampling}

In order to draw comparisons across both categories of actors and levels of government, we drew a sample of Twitter handles-the usernames appear after the @ symbol-representing relevant federal, state, and local agencies/actors, operating in the affected areas. We focused on those government agencies directly responsible for the management of public health emergencies, such as health services and emergency management. Twitter handles were identified by visiting the appropriate individual and institutional websites.

In the case of local governments, analyzing all affected agencies was not feasible or necessary. Based on the Zika outbreak reports, we focused on the four specific counties (Dade, Palm Beach, Broward, and Orange counties) and the four major cities (Miami, Orlando, Fort Lauderdale, West Palm Beach) that had the highest number of case reports for Zika infection during the data collection period. Following these procedures, a total of 14, 5, and 35 Twitter handles were collected for the federal, state, and local levels, respectively. The complete list of sampled Twitter handles is available in Appendix I. We then collected all tweets initiated by these Twitter handles, which totaled 721. For the purposes of content analysis, we randomly sampled 200 tweets from this total, with the unit of analysis being tweets originated by the sampled Twitter handles.

\subsection{Mixed Methods to Measure Social Media Use by Government}

This analysis utilizes a mixed-methods approach to investigate social media usage by public agencies and elected officials. Mixed methods are possible in this case because Twitter includes multiple data points, including quantitative measures such as number of followers, tweets, retweets, and mentions, as well as qualitative data points such as the content of tweets.

We began our analysis by quantitatively investigating the attributes of the tweets as well as the inclusion of multimedia content. The attributes of tweets are important to examine because they can deepen our understanding of influence, communication patterns, and community structures [9, 26, 49]. The most popularly studied attributes of tweets include the number of followers, retweets, and mentions [9]. Cha et al. [9] found that retweets and mentions reflect the influence of a user. Retweets are driven by the content value of a tweet because it brings new people into the discussion even without directly addressing actors [4, 9]. Mentions are driven by the name value of the user and often expected to increase possible retweets to initiate large-scale cascade diffusion of the tweet $[9,37]$. According to Cha et al., while retweets and mentions reflect the influence of a user, the number of followers a user has indicates his or her popularity but does not reveal the user's level of influence [9].

Another important attribute of tweets is the inclusion of multimedia. Twitter users often include URLs, images, videos, and text to overcome the word-length limit (during the data collection the upper limit was 140 characters) in an effort to communicate rich content. Scholars report that a growing number of Twitter users utilize multimedia for information sharing, expressing opinions, and reporting news [10]. Zhao et al. reported that multimedia tweets are more popular and have a longer lifespan compared to text only tweets [66].

Digital Government: Research and Practice, Vol. 1, No. 2, Article 13. Publication date: April 2020. 
Table 1. Coding Rules

\begin{tabular}{|l|l|}
\hline $\begin{array}{l}\text { Information } \\
\text { provision }\end{array}$ & $\begin{array}{l}\text { - Operations: Contents related to operations of the agencies. } \\
\text { - Events: Event information, which tends to include time, date, or links. Invites followers to } \\
\text { tune in to a media appearance. One-way communication only. Therefore, excludes tweets } \\
\text { requesting to submit questions for interactions. } \\
\text { - Social Sharing: Providing contents related to the mission of the agencies but not related } \\
\text { to operations or policies. It includes informative contents that may be of interest, such as } \\
\text { news articles. Providing information and recommendation for the public. Frequently, these } \\
\text { tweets include words like "learn" or "must" or "should" that are intended to promote } \\
\text { behavioral changes. }\end{array}$ \\
\hline $\begin{array}{l}\text { Input } \\
\text { seeking }\end{array}$ & $\begin{array}{l}\text { - Question/Answer: Invites followers to pose or submit questions for a scheduled event, } \\
\text { either online or via telephone (e.g., \#AtoZika campaign to solicit questions from the public). }\end{array}$ \\
\hline Politics & $\begin{array}{l}\text { - Call to Action: Calls for action on Zika without blaming specific political actors/groups. } \\
\text { Calls for action on a specific item or activity. } \\
\text { - Blame: Primary purpose of tweet is to blame the current state of affairs/lack of progress } \\
\text { on political rival. Calls out a specific political actor or political group. } \\
\text { - Self-Promotion: Primary purpose of tweet is self-promotion; talks about what the } \\
\text { politician is or has been doing; plugs media appearance; shows constituency that he/she is } \\
\text { working on the constituency's behalf, meeting with governor, etc. }\end{array}$ \\
\hline $\begin{array}{l}\text { Symbolic } \\
\text { presentation }\end{array}$ & $\begin{array}{l}\text { - Favolic act: Expressing congratulations or gratitude. } \\
\text { Reporting of positive activity performed by the department. }\end{array}$ \\
\hline
\end{tabular}

In addition, we qualitatively investigated the content communicated in the sampled tweets, utilizing a content analysis to allow for further tabulations of differences.

Based on a typology developed by [17], as discussed above, and other literature regarding content analysis of government social media, we developed initial coding rules. Two of the authors created the initial coding scheme using a sample of tweets until no new category emerged. Table 1 shows the content categories we developed for coding 200 tweets.

\section{FINDINGS}

\subsection{Use of Tweets: Attributes}

As discussed above, the number of Twitter handles in each category (i.e., level of government) is uneven: 14, 5, and 35 for federal, state, and local actors, respectively. To correct for this, we have normalized the raw counts by the number of Twitter handles in Table 2, which shows descriptive statistics for the various attributes by level of government. When normalized, federal accounts have on average greater than three times more followers (over 1 million followers per Twitter handle) compared to state-level accounts (over 300,000 per Twitter handle) and 58 times more, on average, than the local agency accounts (19,000 followers per Twitter handle) (see Figure 1). Although their average number of followers is smaller than their federal counterparts, state-level agencies used the highest number of mentions and retweets. Compared to federal and state-level agencies, local agencies had notably fewer followers and used Twitter less actively in all four attributes.

\subsection{Use of Tweets: Multimedia Types}

The most frequently used multimedia type in the sample was URLs (304 tweets), followed by images (132 tweets) (see the "Total" column Table 2). When broken down by level of government, federal agencies used URLs (59\%) the 
Table 2. Attributes/Multimedia Use by Government Levels

\begin{tabular}{|l|r|r|r|r|}
\hline & \multicolumn{1}{|l|}{ Federal } & \multicolumn{1}{|c|}{ State } & \multicolumn{1}{|c|}{ Local } & \multicolumn{1}{c|}{ Total } \\
\hline Twitter handles & 14 & 5 & 35 & 54 \\
Tweets (normalized) & $374(27)$ & $90(18)$ & $257(7)$ & 721 \\
\hline Retweets (normalized) & $8,851(632)$ & $2,916(583)$ & $686(20)$ & 12,453 \\
\hline Mentions (normalized) & $10,866(776)$ & $7,314(1,463)$ & $1,570(45)$ & 19,750 \\
\hline Followers (normalized) & $14,886,468(1,063,319)$ & $1,689,008(337,802)$ & $681,580(19,474)$ & $17,257,056$ \\
\hline Images & 46 & 9 & 88 & 132 \\
\hline Image URLs & 52 & 11 & 38 & 94 \\
\hline Videos & 12 & 13 & 6 & 27 \\
\hline Video URLs & 1 & 0 & - & 1 \\
\hline URLs & 222 & 33 & 97 & 304 \\
\hline Text & 41 & 24 & 27 & 87 \\
\hline Other & 0 & 0 & 1 & 0 \\
\hline
\end{tabular}

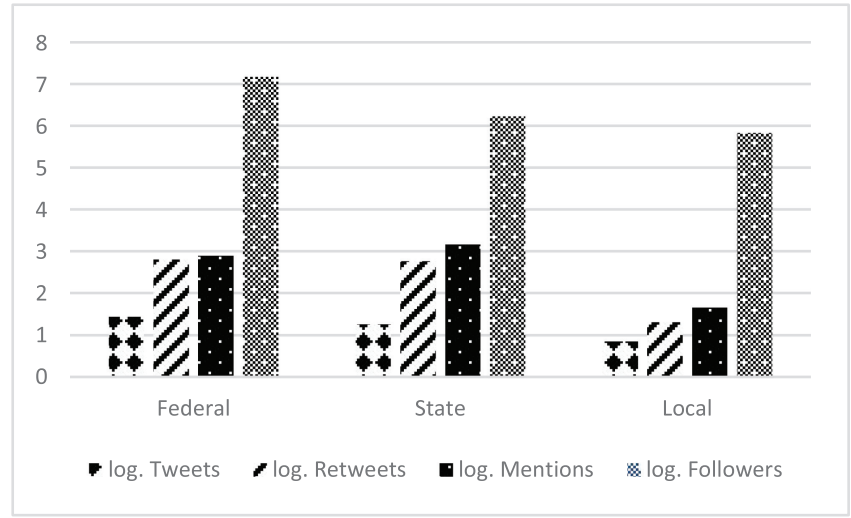

Fig. 1. Attribute distribution by government level. Note: Y-axis is logarithm (base 10) of attribute counts normalized by number of Twitter handles.

most frequently. State-level agencies used URLs (37\%) as well as texts (27\%) frequently. Local agencies frequently used URLs (37\%) and images (33\%). In sum, URLs were the most popular type of multimedia used by government agencies, especially at the federal level, followed by images (see the "Total" column in Table 2). This indicates that Twitter is popularly used for sharing other information sources through URLs or distributing images during health emergencies.

\subsection{Use of Twitter by Level of Government}

4.3.1 Federal Level. Table 3 shows 14 federal-level handles included in our study, which are managed by or affiliated with three major federal agencies: White House, Department of Health and Human Services (HHS), and Centers for Disease Control and Prevention (CDC). Most of the original tweets are created by either the HHS or the numerous Twitter handles associated with the CDC. @HHSGov tweeted the most frequently (81 times), followed by @CDCgov (75 times). An individual account owned by the director of the CDC, @DrFriedenCDC, tweeted very frequently (62 times). In terms of retweets, @WhiteHouse and @CDCgov retweeted the most frequently (4,433 and 1,867, respectively). With regard to mentions, the most highly mentioned handles were 
Table 3. Attributes of the Federal-Level Handles

\begin{tabular}{|c|c|c|c|c|c|}
\hline Twitter Handles & Description & Tweets & Retweets & Mentions & Followers \\
\hline @HHSGov & Department of Health and Human Services & 81 & 731 & 883 & 608,802 \\
\hline @CDCgov & CDC's main account & 75 & 1,867 & 2,954 & 689,374 \\
\hline @CDCChronic & CDC chronic illnesses & 58 & 0 & 0 & 13,634 \\
\hline @CDCemergency & $\begin{array}{l}\text { CDC's Office of Public Health Preparedness } \\
\text { and Response }\end{array}$ & 26 & 101 & 33 & $1,738,872$ \\
\hline @WhiteHouse & The White House's official account & 19 & 4,433 & 1,183 & $11,566,964$ \\
\hline @CDCMMWR & CDC's Morbidity and Mortality Weekly Report & 18 & 55 & 247 & 23,221 \\
\hline @CDCtravel & CDC travel health & 18 & 34 & 16 & 22,592 \\
\hline @CDC_NCBDDD & $\begin{array}{l}\text { CDC National Center on Birth Defects and } \\
\text { Developmental Disabilities }\end{array}$ & 7 & 4 & 12 & 5,487 \\
\hline @CDC_NCEZID & $\begin{array}{l}\text { CDC National Center for Emerging and } \\
\text { Zoonotic Infectious Diseases }\end{array}$ & 6 & 4 & 2 & 5,778 \\
\hline$@$ @DCGlobal & CDC's global health & 4 & 26 & 16 & 109,520 \\
\hline @POTUS & Presidential Twitter account & 0 & 15 & 4,994 & * \\
\hline @BarackObama & Barack Obama's personal account & 0 & 0 & 165 & * \\
\hline$@$ SecSebelius & The secretary of the HHS & 0 & 0 & 0 & * \\
\hline @DrFriedenCDC & Personal account of the director of the CDC & 62 & 1,581 & 361 & 101,647 \\
\hline
\end{tabular}

*The number of followers is not available for Twitter handles, which did not originate tweets in the sample.

Table 4. Attributes of the State-Level Handles

\begin{tabular}{|l|c|c|c|r|}
\hline Twitter Handles & Tweets & Retweets & Mentions & Followers \\
\hline @HealthyFla & 30 & 83 & 452 & 9,144 \\
@FLGovScott & 26 & 410 & 2,342 & 70,490 \\
\hline @senrubiopress & 28 & 1,179 & 128 & 24,103 \\
\hline @marcorubio & 6 & 1,243 & 4,003 & $1,585,271$ \\
\hline @SenBillNelson & 0 & 1 & 389 & $*$ \\
\hline
\end{tabular}

*The number of followers is not available for Twitter handles, which did not originate tweets in the sample.

@POTUS and @CDCgov. The Twitter accounts with the highest followers were @WhiteHouse $(11,566,964)$ and @CDCemergency $(1,739,445)$. During the data collection, @WhiteHouse gained a total of 248,558 followers, and @CDCgov gained 4,639 followers.

4.3.2 State Level. Among the five state-level actors sampled, Florida Senator Marco Rubio's Twitter account, @marcorubio, had the most followers $(1,585,271)$, and mentions $(4,003)$, followed by those of the governor of Florida, @FLGovScott (followers: 70,490 and mentions: 2,342) (see Table 4). This suggests that these two accounts had considerable influence with the public. Another Twitter handle owned by Senator Rubio, @senrubiopress, seemed to be used mainly for tweeting and retweeting purposes. While Senator Rubio's Twitter interaction was extremely high, Florida Senator Bill Nelson used Twitter substantially less often. This seems to coincide with the fact that Senator Rubio was up for re-election at the time of the data collection. Although smaller than that of politicians, the number of tweets originated (30) and mentions (452) by @HealthyFla showed direct efforts by the Florida Department of Health to communicate with the public by updating citizens on the daily spread of Zika, while also sharing critical information related to prevention measures. 
Table 5. Local Level by Multimedia Type and Agency Type

\begin{tabular}{|l|r|r|r|r|r|}
\hline & Mayor & City/County & \multicolumn{1}{c|}{ Rep. } & Health & Emergency Mgmt. \\
\hline Tweets & 37 & 64 & 136 & - & 20 \\
Retweets & 43 & 92 & 540 & - & 11 \\
\hline Mentions & 934 & 314 & 320 & - & 2 \\
\hline Images & 11 & 24 & 49 & - & 4 \\
\hline Image URLs & 12 & 15 & 1 & - & 10 \\
\hline Videos & 1 & 3 & 2 & - & - \\
\hline Video URLs & - & - & - & - & - \\
\hline URLs & 12 & 21 & 59 & - & 5 \\
\hline Text & 1 & 1 & 24 & - & 1 \\
\hline Other & - & - & 1 & - & - \\
\hline Follower & 26,093 & 140,047 & 508,877 & - & 6,563 \\
\hline
\end{tabular}

4.3.3 Local Level. In order to better understand Twitter usage by local agencies, we compared attributes and multimedia usage across different types of local agencies/actors (Table 5). We found that mayors were disproportionately mentioned in comparison to other agencies. Among the seven mayors, Mayor Jacobs of Orlando (@Mayor_facobs) tweeted 32 times, retweeted 23 times, and was mentioned 20 times, and Mayor Gimenez of Miami (@MayorGimenez) tweeted 4 times, retweeted 20 times, and was mentioned 893 times. Other mayors engaged with Twitter very infrequently, close to zero times in most instances (Appendix II).

The fact that some of the mayors were disproportionately active on Twitter during the crisis appears to be related to the number of Zika cases in these mayors' districts as well as the size of the population they serve. For example, Miami-Dade County had the most Zika cases (701 cases by October 2016) and Mayor Gimenez (@MayorGimenez) was heavily engaged with the public via Twitter. In addition, correlation analysis between the population of the local communities and attributes of the sampled tweets revealed that local governments with larger populations tended to more actively employ mentions (Pearson correlation 0.6 with $p$-value $<0.000$, and confidence interval between 0.3 and 0.79 ) compared with less populated municipalities.

The election cycle also appears to be of importance in determining social media activity. @MayorGimenez had extremely high mentions (893), and the fact that the Zika outbreak was a highly important issue for his re-election campaign may explain this. Mayor Jacobs, in contrast, was not up for re-election and the number of mentions (20) was notably lower in his case.

Congressional representatives had the highest follower counts (a total of 508,877) and were very actively engaged in terms of tweeting, retweeting, and mentions (Table 5). Although their number of followers was substantially lower, city and county accounts frequently used Twitter for the same purposes (tweets, retweets, and mentions). The sampled local health agencies did not use Twitter. Out of the five emergency management handles, Miami/Dade County Emergency Management (@miamidadeem) and Orlando Office of Emergency Management (@orloem) used tweets and retweets, but not frequently. In sum, elected office holders such as mayors and congressional representatives were far more active on Twitter during the health crisis than their local government counterparts. In each case, Twitter use appeared to be associated with population sizes and the ongoing election cycles.

\subsection{Elected Officials and Administration}

Additionally, we compared the use of Twitter by elected officials and government agencies across all three levels of government. The results, presented in Figure 2, show that elected officials were far more prolific users of Twitter than public agencies at the state and local levels. In contrast, federal agencies were more likely to actively

Digital Government: Research and Practice, Vol. 1, No. 2, Article 13. Publication date: April 2020. 


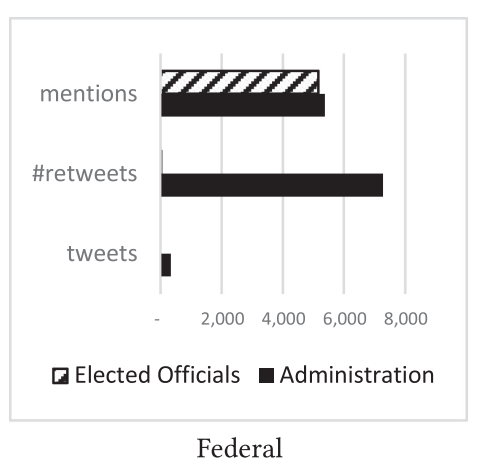

Federal
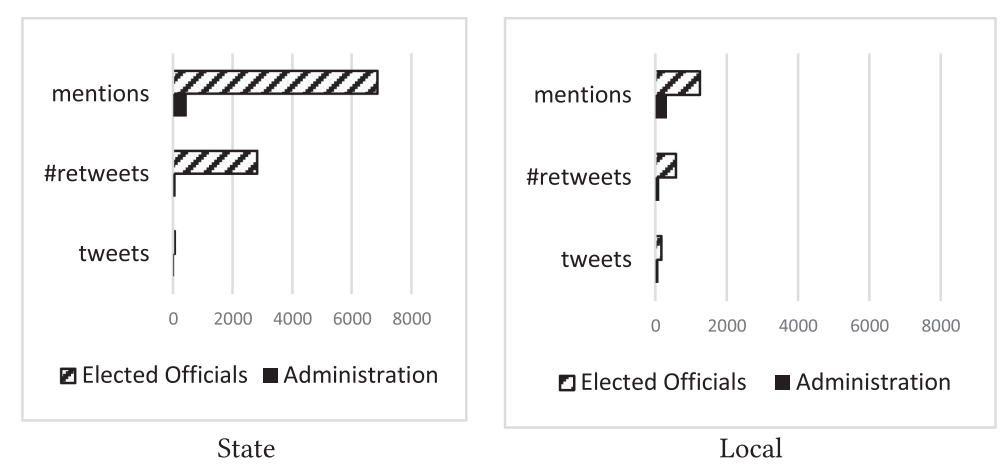

Fig. 2. Use of tweets, retweets, and mentions: Elected officials vs. administration by federal, state, and local levels.

Table 6. Distribution of Tweet Categories by Government Level $(N=200)$

\begin{tabular}{llrrrr}
\hline Category (\%) & Category (Secondary) & Federal & State & Local & Total \\
\hline \multirow{2}{*}{ Information provision (50) } & Operations & 6 & 1 & 4 & 11 \\
& Events & 2 & 0 & 5 & 7 \\
& Social Sharing & 61 & 8 & 12 & 81 \\
Input seeking (11) & & 14 & 0 & 7 & 21 \\
\hline \multirow{2}{*}{ Politics (31) } & Call to Action & 1 & 8 & 10 & 19 \\
& Blame & 5 & 3 & 8 & 16 \\
& Self-Promotion & 2 & 5 & 20 & 27 \\
\multirow{2}{*}{ Symbolic Presentation (9) } & Symbolic Act & 4 & 0 & 3 & 7 \\
& Fav. Presentation & 8 & 0 & 3 & 11 \\
\hline Total & & 103 & 25 & 72 & 200 \\
\hline
\end{tabular}

utilize Twitter during the Zika outbreak (Figure 2). The larger number of followers enjoyed by many elected officials indicates that these actors may have a greater ability to influence the public via social media, suggesting that government agencies charged with protecting the public in times of crisis might do well to consider strategically partnering with elected officials to disseminate crisis information in cases of public emergency.

Another interesting finding is the role of personal accounts. Although not an elected official, a personal account belonging to the director of the CDC, @DrFriedenCDC, had a high number of followers $(101,647)$ and was actively used throughout the outbreak. Hagen et al. found that @DrFriedenCDC was one of the most highly trusted actors for Zika communications on Twitter [26]. This demonstrates that it is important to consider the use of personal accounts in addition to official agency accounts, and to strategize the use of the two for appropriate purposes [45]. In sum, it would be wise to strategically leverage elected officials and the personal accounts of administration officials, in combination with official agency accounts, in order to gain fast reach to wider audiences, due in large part to the substantial follower networks and the flexible nature of these accounts [26].

\subsection{Content Analysis Results}

Using the coding rules outlined in Table 1 above, we conducted a content analysis on 200 randomly drawn tweets from the sample using the $\mathrm{R}$ random number generating function [62]. The majority of the tweets were categorized as information provision (50\%), followed by politics (31\%), input seeking $(11 \%)$, and symbolic presentation (9\%) (see Table 6). However, when analyzed by government level, we find interesting contrasts among them. While federal agencies used tweets predominantly for information provision and input seeking, state and local 


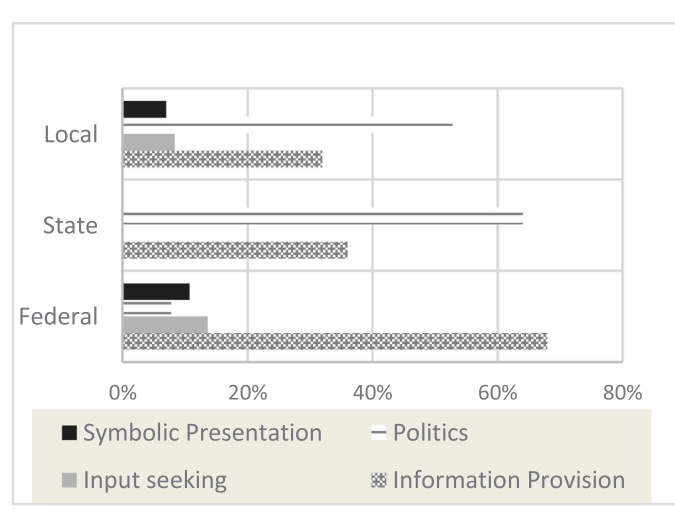

(a) Category: Federal/State/Local

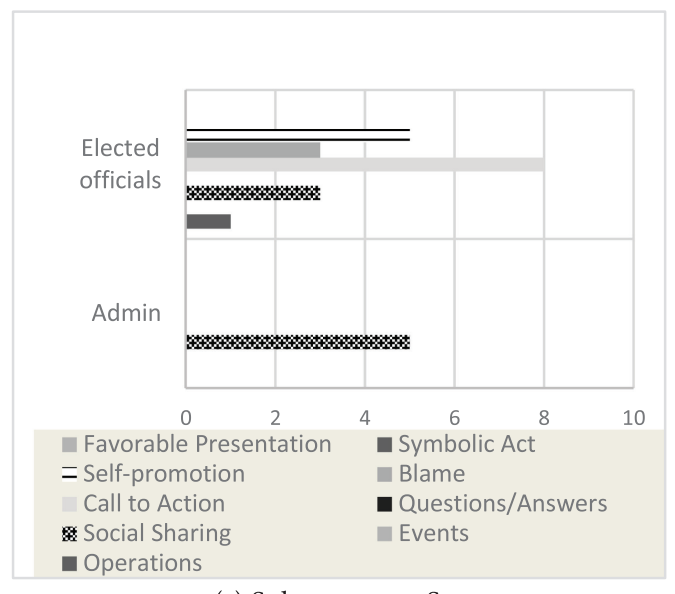

(c) Sub-category: State

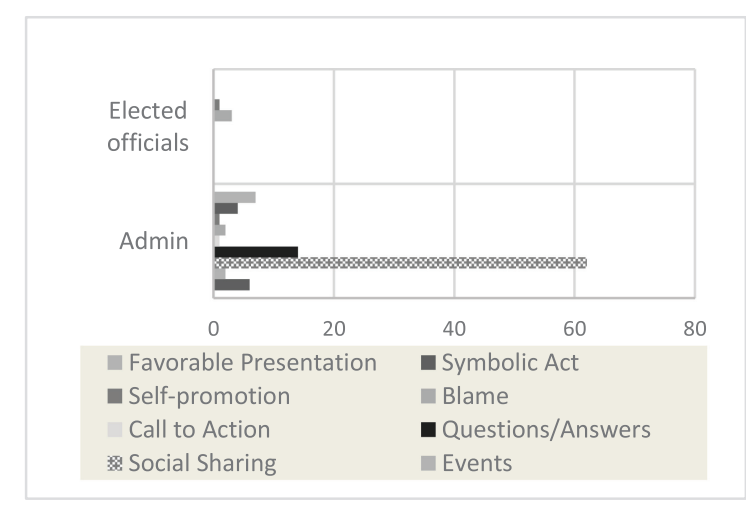

(b) Sub-category: Federal

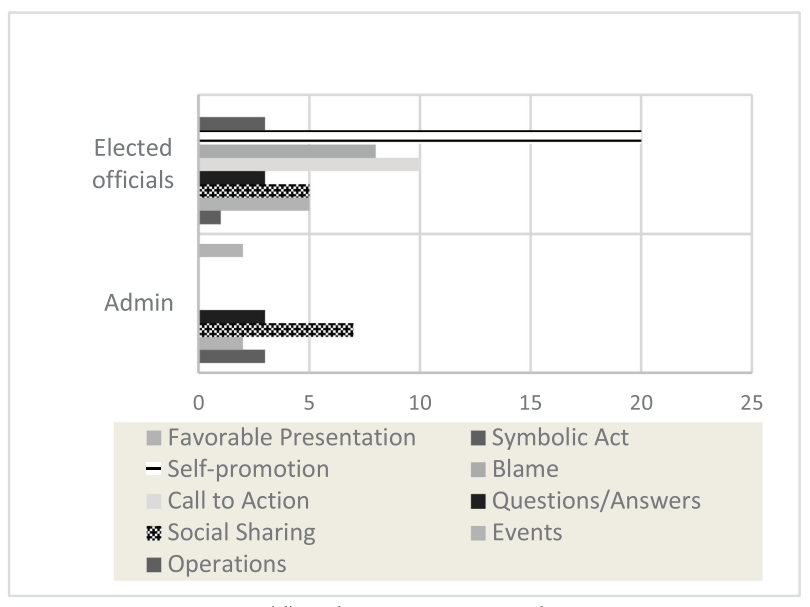

(d) Sub-category: Local

Fig. 3. Content analysis results of federal-, state-, and local-level use of Twitter. Note: Raw numbers are divided by the total number of tweets categorized in the government level.

actors used tweets more commonly for political purposes (Figure 3). Among those tweets categorized as "politics," state actors more commonly fell under the "call to action" subcategory, while local actors were more likely to fall under the "self-promotion" subcategory. These results are discussed in greater detail below.

4.5.1 Information Provision. Among the three subcategories (social sharing, operations, and events), social sharing was predominant (81) followed by operations (11) and event announcements (7). Tweets categorized as social sharing were used to inform citizens about Zika: what was happening and how to prevent the spread of Zika. For example, a tweet originated by @CDCChronic provides expectant mothers with information linked via a URL to prevention measures from mosquito bites: "Everyone, esp. expectant moms, should protect themselves from mosquito bites. My new \#Zika op-ed w. @HeidiMurkoff https://t.co/E3mIwEOsK2.” @HealthyFla tweeted: "\#Florida Department of Health Daily \#Zika Update for September 19, 2016: https://t.co/iqr9KMUUxZ https://t.co/ $4 g I V K W \operatorname{moxB}$," which provides daily updates regarding Zika for citizens. A representative tweeted to inform constituents regarding possible approval of additional Zika funds to help locations affected by Zika outbreaks.

Tweets categorized for operations broadcast governments' effort to control mosquito populations in order to prevent the spread of Zika. For example, @FLGovScott tweeted: “To date, @HealthyFla has provided more than 
2,200 free Zika tests to pregnant women and we will do everything possible to ensure they are safe." @CityofMiami tweeted efforts exerted by Miami police: "Miami Police Give Mosquito Repellent to Homeless in Zika Fight | NBC 6 South Florida https://t.co/GmhLQDBOnl via @nbc6.” Interestingly, the majority of tweets (five out of six) by the federal governments in the operations subcategory are about mosquito spraying, which seems to be an effort to attenuate the public's concerns regarding negative impacts from spraying. This seems to be a response to cases where mosquito spray killed millions of honeybees [67]. For example, @CDCChronic tweeted: "We wish there was a vaccine to prevent \#Zika, but our best efforts right now must include aerial spraying in FL. https:// t.co/s3EYTNWyep."

Both federal and local officials also utilized Twitter for event announcements seven times (see Table 6). These events mainly announced townhall meetings hosted by local and federal authorities to discuss Zika. For example, @CDCgov tweeted: “Starting soon: I’ll be livew. @stavernise at 1:35 ET talking about \#Zika. Watch via @nytimes Facebook page: https://t.co/x1GSs791WO.” A local congressional representative (@RepDWStweets) tweeted: "Discussed the Zika virus and crises in Venezuelawith @caracol1260's @YolyCuello today - tune in at 6 p.m.! https://t.co/xH5yobhA9r," soliciting constituencies to listen to a radio program where the representative appeared to discuss Zika.

4.5.2 Input Seeking. Both federal and local agencies used Twitter for soliciting questions as part of an effort to provide answers to citizens on Zika-related questions. The hashtag campaign \#AtoZika represented one such effort to hear public concerns (i.e., $18 \%$ of the sampled tweets included \#AtoZika). In addition, 19 out of the 21 tweets categorized in the input-seeking category included \#AtoZika. This is a well-orchestrated effort to understand perspectives of citizens. Both federal and local-level government agencies leveraged the affordance of Twitter as an effective tool for live communication. Federal government agencies hosted online townhall meetings, announced the meeting times, and encouraged the public to submit questions before the townhall meeting. For example, the Department of Health and Human Services (@HHSGov) tweeted multiple tweets such as "Travel this summer? Worried about \#Zika? We'll answer your Qs during the \#AtoZika Town Hall on Tuesday (8/30). https:// t.co/lHoEgFExnC." Local governments also tweeted similar tweets in order to encourage the local public to join national online townhall meetings. For example, Orange County (@OrangeCoFL) tweeted: “Don't miss the @HHSGov \#AtoZika Twitter Town Hall tomorrow, Aug. 30, 10 a.m. Submit questions using \#AtoZika. \#Zika https://t.co/9tHM8KaaZQ."

4.5.3 Politics. A large number of the tweets in our sample carried political messages, which were created, retweeted, and mentioned primarily by elected office holders. These actors often tweeted to self-promote their efforts to prevent Zika (a total of 27 tweets). For example, Representative Frederica Wilson, @RepWilson, tweeted: "I promised my district I would fight for a clean \#Zika bill. https://t.co/MtrZZXqPlM." @MayorGimenez tweeted that he requested that high-ranking lawmakers reimburse money to the affected areas in Florida: "Wrote@SpeakerRyan + @SenateMajLdr 2 reimburse \#Florida, @MiamiDade, @CityofMiami, @MiamiBeachNews for\#Zika costs https://t.co/HZridzrfqn". Some politicians expressed frustrations with the politicized nature of the Zika conversation, which they regarded as a nonpartisan public health issue: "The \#Zika virus crisis is about public health-not politics! \#DoYourfob!"

A total of 19 tweets were categorized as call to action. Most of these tweets included the hashtag \#DoYourJob!, calling on the U.S. Congress to take action on the Zika crisis. For example, a local representative, @MarioDB, tweeted: "3 mosquitoes have tested positive in Miami Beach for \#zika-Senate Dems need to consider the bills the House approved 10+ weeks ago.” Another local representative, @RepWilson, tweeted: "\#Zika isn't just a summer problem. Southern \#Zika mosquitos can live through the fall. We need action! \#DoYourfob https://t.co/Qb8EtnZCHK."

A total of 16 additional tweets were classified in the blame category, with most of them blaming Congress for not passing a Zika funding bill. For example, @RepDWStweets blamed Republicans in her tweet: "The Republicans need to drop their \#Zika obstructionism right now. This is a crisis in \#SouthFlorida. https://t.co/

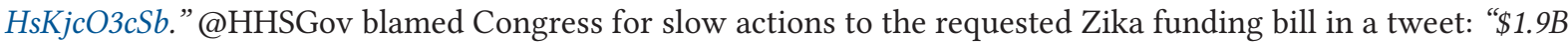


= what @POTUS requested from Congress to fight \#Zika. 200+ days since that request. https://t.co/hPdFepZcwg \#AtoZika."

4.5.4 Symbolic Presentation. Two subcategories of symbolic representation included symbolic act and favorable presentation. Seven tweets were categorized as symbolic acts. These tweets congratulated, expressed gratitude, and provided emotional support for individuals and activities. For example, @HHS tweeted: "Thanks for all your support on \#Zika emergency \$\$. Need it to continue this work. \#atozika https://t.co/Zaxtghfq9f." @Mayor_Jacobs tweeted: "Thanks Mayor for raising \#Zika awareness! Want to know more? Tune-in TOMORROW for full day \#AtoZika twitter townhall https://t.co/b1IUTfgPOb."

Tweets were also used for the purposes of favorable presentation, to highlight what agencies and individuals were doing or to praise agencies' efforts. Eleven tweets are categorized as favorable presentation; most of them sought increased likability and promoted positive activities performed by agencies. For example, @CDC_NCBDDD tweeted: "Proud to partnerwith @modhealthtalk on efforts to save babies. Together, making a difference for babies and families. https://t.co/GqGeqXGXaq". And similarly, @CDCChronic tweeted: "CDC teams continue work to support diagnosis of \#Zika infection as quickly as possible. https://t.co/SUqSDdG5ME https://t.co/AWfo00XfLz."

\section{DISCUSSION}

The purpose of the study is to better understand the use of social media by public officials and government agencies as a crisis and emergency risk communications tool, as well as to examine how patterns of usage might differ across different levels of government during a public health emergency. Using a mixed-methods approach, we found that federal agencies far exceeded state and local governments in their use of Twitter during public health emergencies. We learned that federal-level agencies have extremely large numbers of built networks (i.e., follower counts) and tend to use Twitter for information provision purposes, utilizing URLs in an effort to lead to rich information sources. Additionally, federal agencies were more likely than their state and local counterparts to use Twitter as a means of seeking input from the public, particularly in the form of public-health-related questions. State- and local-level agencies tended to have smaller follower networks and thus utilize Twitter distinctively less frequently compared to the federal actors and agencies. State and local governments appear to still experience some of the challenges of adopting and utilizing social media in these instances.

However, local-level tweets are important because they reflect local governments' and politicians' efforts to address their constituents' anxiety about the spread of Zika as well as their frustrations regarding the lack of action taken by Congress.

Our findings highlighted the role and importance of elected officials in crisis communications. The findings help to add to the CERC literature regarding the importance of engaging with state and local politicians during emergencies (through social media) in order to leverage their influence. Elected officials from the state and local level (senators, governors, representatives, and mayors) were distinctive in their Twitter behavior. They managed large numbers of followers (Appendix I) and more actively engaged with the public via Twitter in comparison to their administrative counterparts (i.e., official Twitter accounts of agencies and departments). Local elected officials were actively engaged with local constituents, especially for publicizing their actions to overcome the crisis and for calls to action. In some sense, this may be partially due to the fact that elected officials are less constrained by limitations compared to government administrators who are limited in their ability to deploy social media by organizational structures, finite resources, and legal dilemmas.

Our findings also highlight the potential for social media to engage multiple participants, such as the public and affected communities, in the process of crisis and emergency response communications. During the Zika health emergency, federal agencies used Twitter to actively learn about citizens' concerns through a hashtag campaign \#AtoZika. Based on recognized public problems, Twitter further was used to announce and deliver the links to live conferences or townhall meetings to answer these questions. These is evidence of using social 
media for engagement with citizens to overcome the crisis through collaborative efforts. Some of the federallevel agencies (i.e., @CDCgov and @HHSGov) leveraged the affordance of Twitter that enables many-to-many communications in order to actively gather information and input from citizens, as well as to answer requests for information in an organized and timely manner-in many cases through live townhall settings.

Finally, we found that Twitter was a useful tool for sharing critical information developed by the federal agencies with state and local governments during health emergencies. Federal government agencies used Twitter to provide relevant information (we coded this as "social sharing") regarding the current status of the disease and to share prevention measures with the public. The majority of social sharing $(75 \%)$ was done by Twitter handles created by two federal agencies-the CDC and HHS. Most of the content was designed to educate the public regarding Zika prevention measures by the CDC. For example, one tweet contained an educational video produced by he $\mathrm{tCDC}$ regarding how to clear standing water: "Mosquitoes that carry \#Zika lay eggs near standing water. Empty, cover, or throw out items that hold water. \#ZapZika https://t.co/YqAH4jPoKL." While the majority of social sharing was initiated by federal actors, state and local governments also created some contents for social sharing. The Florida Department of Health created and shared a video/infographic campaign called "Spill the Water" regarding stopping mosquitoes by reducing sources of standing water: "Tip, Toss and Cover! Learn how you can help prevent \#Zika. https://t.co/VWvRZfCtwN https://t.co/LnvXQfg7BV." These efforts to share information and to educate were not confined to the public. The federal agencies extended their efforts to educate state and local health officials with up-to-date information. This is one example tweet providing Zika response planning tips: "Are you a state, tribal, local or territorial health official? Get the top 10 \#Zika response planning tips https:// t.co/NuWXvZnaDW \#NatlPrep." In addition, the CDC distributed communication materials about Zika such as fact sheets, infographics, posters, and videos for state and local government officials to be distributed to their local constituencies. One example read: "\#HealthDepts: Get communication materials about \#Zika, including fact sheets, infographics, posters, and; videos https://t.co/LaMzi5aLWG.” The sweeping majority (83\%) of tweets for information provision included URLs, which frequently led to infographics designed for health education [63].

\section{CONCLUSIONS}

CERC is a field of study aimed at improving strategic responses during the various stages of a public crisis [13, 55]. Many advances have been made in this area since the 1990s, but it is still challenging to develop theory, research, and best practices that are generalizable and practically useful for crisis decision making. Due to the nature of CERC, case studies provide more insights, "advanced thinking," and advice in crisis communication [12] by analyzing a case bounded by complex real-life contexts [2]. Our study has focused on understanding the public actors in their use of social media for CERC during the 2016 Zika outbreak in the United States. As a result, our study reveals that engaging with elected officials is an effective strategy, particularly for state and local government agencies that do not have a strong presence on social media. This allows public agencies to leverage the larger follower networks enjoyed by elected officials to ensure the timely and effective communication of critical messages. In addition, we found that messages and educational materials developed and communicated by the central agencies are useful for the public as well as for the local agencies who have limited resources to develop campaign materials. Our case study is unique because we investigated actions by actors at multiple levels of government during the crisis response phase.

We believe that this analysis has policy implications for government and emergency communication practitioners, particularly for informing crisis communication strategies. Our findings provide specific social media strategies, particularly for state and local government agencies and actors. Local governments in particular can increase their social media activity and utilize the powerful connections of their elected officials during crisis situations. It would be wise to regularly update social media accounts, such as Twitter handles, not only for administrative accounts-including useful unofficial accounts managed by administrators-but also for elected office holders. In addition, during crisis situations, a unified hashtag campaign can help in actively listening 
to citizens' concerns and promptly responding to those concerns. This way, our findings can benefit governments' effort to develop an emergency toolkit for crisis communications by providing strategies on how to take advantage of social media during emergencies [15].

This study also provides knowledge on input-seeking strategies utilized by government agencies during emergencies. Input seeking was done in order to actively listen to citizens' perspectives and to provide timely and needed service and information for the public. This way, input seeking seemed to function as a preparation for immediate and meaningful interaction with citizens during health crisis situations.

Our study has focused on investigating public actors during crisis. And, methodologically, this study provides quantitative and qualitative measures for social media use so that practitioners and scholars can learn useful insights from social media data. Future studies may need to consider investigating the interplay between official information and citizens' reactions. This type of research will contribute to providing measures of effectiveness and efficiency [46] of official information based on citizens' level of engagement and motivations. In addition, it will improve our understanding of the demand side of social media [14], which will further contribute to creating effective strategies for networking and transactional use of social media. One more limitation to note is about generalizability. This is a case study using a sample of Twitter data for a single topic, which limits the generalizability of the findings. Future studies using larger samples from different social media platforms and a variety of discussion threads can strengthen generalizability of the findings. Our findings may serve as a basis for theory testing in future studies.

\section{APPENDIX I. FULL LIST OF TWITTER HANDLES AND ATTRIBUTES}

\begin{tabular}{|c|c|c|c|c|c|c|c|}
\hline & Twitter Handle & Account Holder & Status & Tweet & Retweet & Mention & Follower \\
\hline \multirow[t]{14}{*}{ Federal } & WhiteHouse & White House & & 19 & 4,433 & 1,183 & $11,566,964$ \\
\hline & $\underline{\text { POTUS }}$ & $\underline{\text { President }}$ & & $\mathbf{0}$ & 15 & 4,994 & - \\
\hline & BarackObama & $\underline{\text { Obama }}$ & & $\mathbf{0}$ & $\mathbf{0}$ & 165 & - \\
\hline & HHSGov & HHS.gov & $\begin{array}{l}\text { Dept. of Health and Human } \\
\text { Services }\end{array}$ & 81 & 731 & 883 & 608,802 \\
\hline & SecSebelius & Kathleen Sebelius & Former secretary of HHS & 0 & 0 & 0 & - \\
\hline & DrFriedenCDC & Tom Frieden & Former director of the $\mathrm{CDC}$ & 62 & 1,581 & 361 & 101,647 \\
\hline & CDCtravel & CDC Travel Health & & 18 & 34 & 16 & 22,592 \\
\hline & CDC_NCBDDD & CDC_NCBDDD & $\begin{array}{l}\text { National Center on Birth Defects } \\
\text { and Developmental Disabilities }\end{array}$ & 7 & 4 & 12 & 5,487 \\
\hline & CDCGlobal & CDC Global Health & & 4 & 26 & 16 & 109,520 \\
\hline & CDCgov & $\mathrm{CDC}$ & $\begin{array}{l}\text { Centers for Disease Control and } \\
\text { Prevention }\end{array}$ & 75 & 1,867 & 2954 & 689,374 \\
\hline & CDC_NCEZID & & $\begin{array}{l}\text { National Center for Emerging } \\
\text { and Zoonotic Infectious Diseases }\end{array}$ & 6 & 4 & 2 & 5,778 \\
\hline & CDCChronic & & CDC chronic illnesses & 58 & 0 & 0 & 13,634 \\
\hline & CDCMMWR & & $\begin{array}{l}\text { Morbidity and Mortality Weekly } \\
\text { Report }\end{array}$ & 18 & 55 & 247 & 23,221 \\
\hline & CDCemergency & CDCemergency & & 26 & 101 & 33 & $1,738,872$ \\
\hline \multirow[t]{5}{*}{ State } & $\underline{\text { marcorubio }}$ & Marco Rubio & Senator & 6 & 1,243 & 4,003 & $1,585,271$ \\
\hline & senrubiopress & $\begin{array}{l}\text { Senator Rubio } \\
\underline{\text { Press }}\end{array}$ & & 28 & 1,179 & 128 & 24,100 \\
\hline & $\underline{\text { FLGovScott }}$ & $\underline{\text { Rick Scott }}$ & Governor & 26 & 410 & 2,342 & 70,490 \\
\hline & SenBillNelson & $\underline{\text { Bill Nelson }}$ & & 0 & 1 & 389 & - \\
\hline & HealthyFla & $\begin{array}{l}\text { Florida Dept. of } \\
\text { Health }\end{array}$ & & 30 & 83 & 452 & 9,144 \\
\hline
\end{tabular}

Digital Government: Research and Practice, Vol. 1, No. 2, Article 13. Publication date: April 2020. 


\begin{tabular}{|c|c|c|c|c|c|c|c|c|}
\hline & & Twitter Handle & Account Holder & Status & Tweet & Retweet & Mention & Follower \\
\hline \multirow[t]{29}{*}{ Local } & \multirow{7}{*}{ Mayor } & MayorGimenez & $\underline{\text { Carlos A Gimenez }}$ & Mayor of Miami-Dade County & 4 & 20 & 893 & 8,679 \\
\hline & & Tomas_Regalado & Thomas Regalado & Mayor of city of Miami & 1 & 0 & 20 & 9,539 \\
\hline & & Mayor_Jacobs & Mayor Teresa & Orange County mayor & 32 & 23 & 20 & 7,875 \\
\hline & & orlandomayor & $\frac{\text { Mayor Buddy }}{\text { Dyer }}$ & Orlando mayor & 0 & 0 & 1 & - \\
\hline & & JackSeiler & $\underline{\text { Mayor Jack Seiler }}$ & Mayor of Fort Lauderdale & 0 & 0 & 0 & - \\
\hline & & MartyKiar & Marty Kiar & Broward County mayor & 0 & 0 & 0 & - \\
\hline & & jmuoio & $\underline{\text { Jeri Muoio }}$ & Mayor of West Palm Beach & 0 & 0 & 0 & - \\
\hline & \multirow[t]{22}{*}{ City/County } & MiamiDadeCounty & $\begin{array}{l}\text { Miami-Dade } \\
\text { County }\end{array}$ & & 2 & 0 & 182 & 37,322 \\
\hline & & pbcgov & Palm Beach County & & 3 & 1 & 11 & 20,844 \\
\hline & & BrowardCounty & $\begin{array}{l}\text { Broward County } \\
\text { Gov. }\end{array}$ & & 2 & 3 & 15 & 4,008 \\
\hline & & OrangeCoFL & Orange County, FL & & 38 & 54 & 24 & 14,493 \\
\hline & & CityofMiami & City of Miami & City of Miami & 19 & 34 & 78 & 63,380 \\
\hline & & citybeautiful & Orlando, FL & City of Orlando & 0 & 0 & 3 & - \\
\hline & & ftlcitynews & $\begin{array}{l}\text { City of Fort } \\
\text { Lauderdale }\end{array}$ & City of Fort Lauderdale & 0 & 0 & 1 & - \\
\hline & & westpalmbch & West Palm Beach & City of West Palm Beach & 0 & 0 & 0 & - \\
\hline & & repstephmurphy & $\frac{\text { Rep Stephanie }}{\text { Murphy }}$ & $\begin{array}{l}\text { 7th district - Winter Park - } \\
\text { Orange, Seminole }\end{array}$ & 0 & 0 & 0 & - \\
\hline & & congbillposey & $\underline{\text { Bill Posey }}$ & $\begin{array}{l}\text { 8th district - Rockledge - } \\
\text { Brevard, Indian River, Orange }\end{array}$ & 0 & 0 & 3 & - \\
\hline & & $\underline{\text { RepDarrenSoto }}$ & $\begin{array}{l}\text { US Rep. Darren } \\
\text { Soto }\end{array}$ & $\begin{array}{l}\text { 9th district - Orlando - Osceola, } \\
\text { Orange, Polk }\end{array}$ & 0 & 0 & 0 & - \\
\hline & & RepValDemings & $\underline{\text { Rep. Val Demings }}$ & 10th district - Orlando - Orange & 0 & 0 & 0 & - \\
\hline & & $\underline{\text { RepBrianMast }}$ & $\underline{\text { Rep. Brian Mast }}$ & $\begin{array}{l}\text { 18th district - Hutchinson Island } \\
\text { - Palm Beach, Martin, St. Lucie }\end{array}$ & 0 & 0 & 0 & - \\
\hline & & $\underline{\text { RepHastingsFL }}$ & Alcee L. Hastings & $\begin{array}{l}\text { 20th district - Broward, Hendry, } \\
\text { Palm Beach }\end{array}$ & 0 & 4 & 4 & - \\
\hline & & RepLoisFrankel & $\underline{\text { Rep. Lois Frankel }}$ & $\begin{array}{l}\text { 21st district - West Palm Beach - } \\
\text { Broward, Palm Beach }\end{array}$ & 15 & 18 & 11 & 8,659 \\
\hline & & $\underline{\text { RepTedDeutch }}$ & $\underline{\text { Rep. Ted Deutch }}$ & $\begin{array}{l}\text { 22nd district - Boca Raton - } \\
\text { Broward, Palm Beach }\end{array}$ & 12 & 43 & 28 & 14,894 \\
\hline & & $\underline{\text { DWStweets }}$ & $\underline{\text { D wasserman }}$ & $\begin{array}{l}\text { 23rd district - Weston - Broward, } \\
\text { Miami-Dade }\end{array}$ & 1 & 52 & 96 & 355,264 \\
\hline & & RepDWStweets & $\frac{\text { D. Wasserman }}{\underline{\text { Schultz }}}$ & $\begin{array}{l}\text { 23rd district - Weston - Broward, } \\
\text { Miami-Dade }\end{array}$ & 15 & 118 & 19 & 8,307 \\
\hline & & RepWilson & $\frac{\text { Rep Frederica }}{\underline{\text { Wilson }}}$ & $\begin{array}{l}\text { 24th district - Miami Gardens - } \\
\text { Miami-Dade, Broward }\end{array}$ & 32 & 76 & 56 & 13,222 \\
\hline & & MarioDB & $\underline{\text { Mario Diaz-Balart }}$ & $\begin{array}{l}\text { 25th district - Miami - } \\
\text { Miami-Dade, Collier, Hendry, } \\
\text { Broward }\end{array}$ & 18 & 60 & 35 & 22,117 \\
\hline & & $\underline{\text { RepCurbelo }}$ & $\frac{\text { Rep. Carlos }}{\text { Curbelo }}$ & $\begin{array}{l}\text { 26th district - Kendall - } \\
\text { Miami-Dade, Monroe }\end{array}$ & 7 & 37 & 18 & 6,154 \\
\hline & & RosLehtinen & $\begin{array}{l}\text { Ileana } \\
\text { Ros-Lehtinen }\end{array}$ & $\begin{array}{l}\text { 27th district - Miami - } \\
\text { Miami-Dade }\end{array}$ & 36 & 132 & 50 & 80,251 \\
\hline
\end{tabular}




\begin{tabular}{|c|c|c|c|c|c|c|c|}
\hline & Twitter Handle & Account Holder & Status & Tweet & Retweet & Mention & Follower \\
\hline \multirow[t]{8}{*}{ Health } & FLHealthBroward & FLHealthBroward & Broward Department of Health & 0 & 0 & 0 & - \\
\hline & - & Orlando Health & - & 0 & 0 & 0 & - \\
\hline & - & Miami Health & - & 0 & 0 & 0 & - \\
\hline & - & $\begin{array}{l}\text { West Palm Beach } \\
\text { Health }\end{array}$ & - & 0 & 0 & 0 & - \\
\hline & - & $\begin{array}{l}\text { Fort Lauderdale } \\
\text { Health }\end{array}$ & - & 0 & 0 & 0 & - \\
\hline & - & $\begin{array}{l}\text { Orange County } \\
\text { Health }\end{array}$ & - & 0 & 0 & 0 & - \\
\hline & - & $\begin{array}{l}\text { Palm Beach County } \\
\text { Health }\end{array}$ & - & 0 & 0 & 0 & - \\
\hline & - & $\begin{array}{l}\text { Miami-Dade } \\
\text { County Health }\end{array}$ & - & 0 & 0 & 0 & - \\
\hline \multirow[t]{8}{*}{$\begin{array}{l}\text { Emergency } \\
\text { Management }\end{array}$} & orloem & $\begin{array}{l}\text { Orlando Office of } \\
\text { Emergency } \\
\text { Management (OEM) }\end{array}$ & Orlando OEM & 7 & 8 & 0 & 1,968 \\
\hline & MiamiDEM & $\begin{array}{l}\text { Miami Emergency } \\
\text { Management }\end{array}$ & Miami OEM & 1 & 0 & 2 & 231 \\
\hline & & & Fort Lauderdale OEM & 0 & 0 & 0 & - \\
\hline & & & West Palm Beach OEM & 0 & 0 & 0 & - \\
\hline & readybroward & Broward County, FL & Broward County OEM & 0 & 0 & 0 & - \\
\hline & pbcdem & $\begin{array}{l}\text { PBC Emergency } \\
\text { Management }\end{array}$ & Palm Beach County OEM & 0 & 0 & 0 & - \\
\hline & miamidadeem & $\begin{array}{l}\text { Miami-Dade } \\
\text { County Emergency } \\
\text { Management (EM) }\end{array}$ & Miami-Dade County OEM & 12 & 3 & 0 & 4,361 \\
\hline & & $\begin{array}{l}\text { Orange County } \\
\text { OEM }\end{array}$ & & 0 & 0 & 0 & - \\
\hline \multicolumn{4}{|l|}{ Total } & 721 & 12,453 & 19,750 & \\
\hline
\end{tabular}

Note: The bold, underlined entities represent elected officials. The number of followers is not available for Twitter handles, which did not originate tweets in the sample.

\section{APPENDIX II. LOCAL COMMUNITY SIZE AND SOCIAL MEDIA USE}

\begin{tabular}{|c|c|c|c|c|c|c|c|c|}
\hline & Twitter Handle & Status & Tweet & Retweet & Mention & $\begin{array}{c}\text { Twitter Activity } \\
\text { (Tweet + Retweet } \\
\text { + Mention) }\end{array}$ & Followers & Population \\
\hline \multirow[t]{7}{*}{ Mayor } & MayorGimenez & Mayor of Miami-Dade County & 4 & 20 & 893 & 917 & 8,679 & $2,712,945$ \\
\hline & Tomas_Regalado & Mayor of city of Miami & 1 & 0 & 20 & 21 & 9,539 & 453,579 \\
\hline & Mayor_Jacobs & Orange County mayor & 32 & 23 & 20 & 75 & 7,875 & $1,314,367$ \\
\hline & orlandomayor & Orlando mayor & 0 & 0 & 1 & 1 & - & 277,173 \\
\hline & JackSeiler & Mayor of Fort Lauderdale & 0 & 0 & 0 & 0 & - & 178,752 \\
\hline & MartyKiar & Broward County mayor & 0 & 0 & 0 & 0 & & $1,909,632$ \\
\hline & jmuoio & Mayor of West Palm Beach & 0 & 0 & 0 & 0 & - & 108,161 \\
\hline \multirow[t]{4}{*}{ City/County } & MiamiDadeCounty & Miami-Dade County & 2 & 0 & 182 & 184 & 37,322 & $2,712,945$ \\
\hline & pbcgov & Palm Beach County & 3 & 1 & 11 & 15 & 20,844 & $1,443,810$ \\
\hline & BrowardCounty & Broward County Gov. & 2 & 3 & 15 & 20 & 4,008 & $1,909,632$ \\
\hline & OrangeCoFL & Orange County, FL & 38 & 54 & 24 & 116 & 14,493 & $1,314,367$ \\
\hline
\end{tabular}

Digital Government: Research and Practice, Vol. 1, No. 2, Article 13. Publication date: April 2020. 


\begin{tabular}{|c|c|c|c|c|c|c|c|}
\hline Twitter Handle & Status & Tweet & Retweet & Mention & $\begin{array}{c}\text { Twitter Activity } \\
\text { (Tweet + Retweet } \\
\text { + Mention) }\end{array}$ & Followers & Population \\
\hline CityofMiami & City of Miami & 19 & 34 & 78 & 131 & 63,380 & 453,579 \\
\hline citybeautiful & City of Orlando & 0 & 0 & 3 & 3 & - & 277,173 \\
\hline ftlcitynews & City of Fort Lauderdale & 0 & 0 & 1 & 1 & - & 178,752 \\
\hline westpalmbch & City of West Palm Beach & 0 & 0 & 0 & 0 & - & 108,161 \\
\hline repstephmurphy & $\begin{array}{l}\text { 7th district - Winter Park - } \\
\text { Orange, Seminole }\end{array}$ & 0 & 0 & 0 & 0 & - & 762,326 \\
\hline congbillposey & $\begin{array}{l}\text { 8th district - Rockledge - } \\
\text { Brevard, Indian River, Orange }\end{array}$ & 0 & 0 & 3 & 3 & - & 744,430 \\
\hline RepDarrenSoto & $\begin{array}{l}\text { 9th district - Orlando - Osceola, } \\
\text { Orange, Polk }\end{array}$ & 0 & 0 & 0 & 0 & - & 832,753 \\
\hline RepValDemings & 10th district - Orlando - Orange & 0 & 0 & 0 & 0 & - & 791,447 \\
\hline RepBrianMast & $\begin{array}{l}\text { 18th district - Hutchinson Island } \\
\text { - Palm Beach, Martin, St. Lucie }\end{array}$ & 0 & 0 & 0 & 0 & - & 754,652 \\
\hline RepHastingsFL & $\begin{array}{l}\text { 20th district - Broward, Hendry, } \\
\text { Palm Beach }\end{array}$ & 0 & 4 & 4 & 8 & - & 794,621 \\
\hline RepLoisFrankel & $\begin{array}{l}\text { 21st district - West Palm Beach - } \\
\text { Broward, Palm Beach }\end{array}$ & 15 & 18 & 11 & 44 & 8,659 & 758,201 \\
\hline RepTedDeutch & $\begin{array}{l}\text { 22nd district - Boca Raton - } \\
\text { Broward, Palm Beach }\end{array}$ & 12 & 43 & 28 & 83 & 14,894 & 737,019 \\
\hline DWStweets & $\begin{array}{l}\text { 23rd district - Weston - } \\
\text { Broward, Miami-Dade }\end{array}$ & 1 & 52 & 96 & 149 & 355,264 & 749,377 \\
\hline RepDWStweets & $\begin{array}{l}\text { 23rd district - Weston - } \\
\text { Broward, Miami-Dade }\end{array}$ & 15 & 118 & 19 & 152 & 8,307 & 749,377 \\
\hline RepWilson & $\begin{array}{l}\text { 24th district - Miami Gardens - } \\
\text { Miami-Dade, Broward }\end{array}$ & 32 & 76 & 56 & 164 & 13,222 & 749,624 \\
\hline MarioDB & $\begin{array}{l}\text { 25th district - Miami - } \\
\text { Miami-Dade, Collier, Hendry, } \\
\text { Broward }\end{array}$ & 18 & 60 & 35 & 113 & 22,117 & 763,628 \\
\hline RepCurbelo & $\begin{array}{l}\text { 26th district - Kendall - } \\
\text { Miami-Dade, Monroe }\end{array}$ & 7 & 37 & 18 & 62 & 6,154 & 788,816 \\
\hline RosLehtinen & $\begin{array}{l}\text { 27th district - Miami - } \\
\text { Miami-Dade }\end{array}$ & 36 & 132 & 50 & 218 & 80,251 & 747,049 \\
\hline
\end{tabular}

Note: The number of followers is not available for Twitter handles, which did not originate tweets in the sample.

\section{ACKNOWLEDGMENTS}

We appreciate the valuable feedback from the anonymous reviewers. A previous version of this article was published in "Government Social Media Communications during Zika Health Crisis." In the Proceedings of 19th Annual International Conference on Digital Government Research (Delft, Netherlands, 2018), 10.

\section{REFERENCES}

[1] American Red Cross. 2012. More Americans Using Mobile Apps in Emergencies.

[2] S.-K. An and I.-H. Cheng. 2010. Crisis communication research in public relations journals: Tracking research trends over thirty years. In The Handbook of Crisis Communication, W. T. Coombs and S. J. Holladay (Eds.). Wiley-Blackwell, 65-90.

[3] J. C. Bertot, P. T. Jaeger, and J. M. Grimes. 2010. Using ICTs to create a culture of transparency: E-government and social media as openness and anti-corruption tools for societies. Government Information Quarterly 27, 3 (2010), 264-271. https://doi.org/10.1016/j.giq. 2010.03.001

[4] D. Boyd et al. 2010. Tweet, tweet, retweet: Conversational aspects of retweeting on Twitter. In 2010 43rd Hawaii International Conference on System Sciences (HICSS'10). 1-10.

[5] J. Bright et al. 2017. Does campaigning on social media make a difference? Evidence from candidate use of Twitter during the 2015 and 2017 UK Elections. ArXiv:1710.07087 [cs]. (2017). 
[6] A. D. Brown. 1994. Politics, symbolic action and myth making in pursuit of legitimacy. Organization Studies 15, 6 (1994), $861-878$. https://doi.org/10.1177/017084069401500605

[7] M. J. Canel and K. Sanders. 2012. Government communication: An emerging field in political communication research. In The Sage Handbook of Political Communication, H. Semetko and M. Scammell (Eds.). SAGE Publications Ltd., 85-96.

[8] CERC. 2018. Introduction. Retrieved from https:/www.emergency.cdc.gov/cerc/ppt/CERC_Introduction.pdf.

[9] M. Cha et al. 2010. Measuring user influence in Twitter: The million follower fallacy. ICWSM 10, 10-17 (2010), 30.

[10] E. Chung and J. Yoon. 2016. Image use in social network communication: A case study of tweets on the Boston marathon bombing. Information Research 21, 1 (2016).

[11] S. P. Conrado et al. 2016. Managing social media uncertainty to support the decision making process during emergencies. fournal of Decision Systems 25, sup1 (2016), 171-181.

[12] W. T. Coombs. 2010. Parameters for crisis communication. In The Handbook of Crisis Communication, W. T. Coombs and S. J. Holladay (Eds.). Wiley-Blackwell.

[13] W. T. Coombs and S. J. Holladay. 2010. The Handbook of Crisis Communication. Wiley-Blackwell.

[14] J. I. Criado et al. 2013. Government innovation through social media. Government Information Quarterly 30, 4 (2013), 319-326. https: //doi.org/10.1016/j.giq.2013.10.003

[15] L. Crudele. 2016. A Blueprint for Crisis Communications in Local Government. Retrieved on 13 January, 2018 from http://www.govtech. com/social/A-Blueprint-for-Crisis-Communications-in-Local-Government.html.

[16] Daily Florida Zika virus tracker. 2017. Retrieved February 17, 2019, from http://www.miamiherald.com/news/health-care/ article66790817.html.

[17] N. DePaula, E. Dincelli, and T. M. Harrison. 2018. Toward a typology of government social media communication: Democratic goals, symbolic acts and self-presentation. Government Information Quarterly35, 1 (Jan. 2018), 98-108. DOI : https://doi.org/10.1016/j.giq.2017. 10.003

[18] P. L. Francia. 2018. Free media and Twitter in the 2016 presidential election: The unconventional campaign of Donald Trump. Social Science Computer Review 36, 4 (2018), 440-455. https://doi.org/10.1177/0894439317730302

[19] I. C.-H. Fung et al. 2014. Ebola and the social media. Lancet 384, 9961 (2014), 2207. https://doi.org/10.1016/S0140-6736(14)62418-1

[20] X. Gao and J. Lee. 2017. E-government services and social media adoption: Experience of small local governments in Nebraska state. Government Information Quarterly 34, 4 (2017), 627-634. https://doi.org/10.1016/j.giq.2017.09.005

[21] M. Graham and E. Avery. 2013. Government public relations and social media: An analysis of the perceptions and trends of social media use at the local government level. Public Relations fournal 7, 4 (2013), 1-21.

[22] M. W. Graham et al. 2015. The role of social media in local government crisis communications. Public Relations Review 41, 3 (2015), 386-394.

[23] T. Graham et al. 2013. Between broadcasting political messages and interacting with voters. Information, Communication \& Society 16 , 5 (2013), 692-716. https://doi.org/10.1080/1369118X.2013.785581

[24] S. Greenwood et al. 2016. Social media update 2016. Pew Research Center: Internet, Science \& Tech.

[25] E. Guskin and P. Hitlin. 2012. Hurricane Sandy and Twitter. Pew Research Center's fournalism Project.

[26] L. Hagen et al. 2018. Crisis communications in the age of social media: A network analysis of Zika-related tweets. Social Science Computer Review 36, 5 (2018), 523-541. https://doi.org/10.1177/0894439317721985

[27] M. J. Hatch and M. Schultz. 1997. Relations between organizational culture, identity and image. European fournal of Marketing 31, 5/6 (1997), 10.

[28] K. S. Hennessy. 2012. Are city governments and social media a good match? Quality Cities.

[29] A. L. Hughes and L. Palen. 2012. The evolving role of the public information officer: An examination of social media in emergency management. Fournal of Homeland Security and Emergency Management 9, 1 (2012). https://doi.org/10.1515/1547-7355.1976

[30] A. Jungherr. 2016. Twitter use in election campaigns: A systematic literature review. Journal of Information Technology \& Politics 13, 1 (2016), 72-91.

[31] M. Karakizia. 2015. The impact of social media in the public sector. Procedia - Social and Behavioral Sciences 175, (2015), 384-392.

[32] J. Katz et al. 2013. The Social Media President: Barack Obama and the Politics of Digital Engagement. Palgrave Macmillan US.

[33] M. Latonero and I. Shklovski. 2011. Emergency management, Twitter, and social media evangelism. International fournal of Information Systems for Crisis Response and Management 3, 4 (2011), 1-16.

[34] G. Lee and Y. H. Kwak. 2012. An open government maturity model for social media-based public engagement. Government Information Quarterly 29, 4 (2012), 492-503. https://doi.org/10.1016/j.giq.2012.06.001

[35] M. Lee. 2002. Intersectoral differences in public affairs: the duty of public reporting in public administration. Journal of Public Affairs 2, 2 (2002), 33-43. https://doi.org/10.1002/pa.92

[36] C. Leston-Bandeira and D. Bender. 2013. How deeply are parliaments engaging on social media? Information Polity: The International fournal of Government \& Democracy in the Information Age 18, 4 (2013), 281-297.

[37] Y. Li et al. 2016. Confirmatory analysis on influencing factors when mention users in Twitter. Web Technologies and Applications (2016), $112-121$.

Digital Government: Research and Practice, Vol. 1, No. 2, Article 13. Publication date: April 2020. 
[38] B. Liu and J. Suzanne Horsley. 2007. The government communication decision wheel: Toward a public relations model for the public sector. Journal of Public Relations Research 19, 4 (2007), 377-393. https://doi.org/10.1080/10627260701402473

[39] M. Madden and K. Zickuhr. 2011. 65\% of online adults use social networking sites. Pew Research Center: Internet, Science \& Tech.

[40] S. C. McGregor et al. 2017. Twitter as a tool for and object of political and electoral activity: Considering electoral context and variance among actors. Fournal of Information Technology \& Politics 14, 2 (2017), 154-167. https://doi.org/10.1080/19331681.2017.1308289

[41] J. G. McNutt. 2008. Advocacy organizations and the organizational digital divide. Currents: New Scholarship in the Human Services 7, 2 (2008), 1-13.

[42] K. McNutt. 2014. Public engagement in the Web 2.0 era: Social collaborative technologies in a public sector context. Canadian Public Administration-Administration Publique Du Canada 57, 1 (2014), 49-70. https://doi.org/10.1111/Capa.12058

[43] A. Meijer and M. Thaens. 2013. Social media strategies: Understanding the differences between North American police departments. Government Information Quarterly 30, 4 (2013), 343-350. https://doi.org/10.1016/j.giq.2013.05.023

[44] R. M. Merchant et al. 2011. Integrating social media into emergency-preparedness efforts. New England fournal of Medicine 365, 4 (2011), 289-291. https://doi.org/10.1056/NEJMp1103591

[45] I. Mergel. 2017. Social media communication modes in government. In Routledge Handbook on Information Technology in Government, Y.-C. Chen and M. J. Ahn (Eds.). Routledge. 168-179.

[46] I. Mergel. 2012. The social media innovation challenge in the public sector. Information Polity: The International fournal of Government \& Democracy in the Information Age 17, 3/4 (2012), 281-292.

[47] K. Mossberger et al. 2013. Connecting citizens and local governments? Social media and interactivity in major U.S. cities. Government Information Quarterly 30, 4 (2013), 351-358. https://doi.org/10.1016/j.giq.2013.05.016

[48] L. D. Nelson et al. 2009. Learning from the media in the aftermath of a crisis: Findings from the Minneapolis bridge collapse. Electronic News 3, 4 (2009), 176-192. https://doi.org/10.1080/19312430903300046

[49] M. E. J. Newman. 2006. Modularity and community structure in networks. Proceedings of the National Academy of Sciences 103, 23 (2006), 8577-8582. https://doi.org/10.1073/pnas.0601602103

[50] News Use Across Social Media Platforms 2018 | Pew Research Center. 2018. Retrieved February 25, 2019, from http://www.journalism. org/2018/09/10/news-use-across-social-media-platforms-2018/.

[51] D. F. Norris and C. G. Reddick. 2013. E-participation among American local governments. In Electronic Participation: Proceedings of the 5th IFIP WG 8.5 International Conference, ePart 2013 8075, (2013), 37-48.

[52] Open Government Directive. 2009. Retrieved February 1, 2018, from https://obamawhitehouse.archives.gov/node/7011.

[53] L. Palen and S. B. Liu. 2007. Citizen communications in crisis: Anticipating a future of ICT-supported public participation. In Proceedings of the SIGCHI Conference on Human Factors in Computing Systems. 727-736.

[54] A. Perrin. 2015. Social Media Usage: 2005-2015. Pew Research Center: Internet, Science \& Tech.

[55] B. Reynolds and W. Seeger, M. 2005. Crisis and emergency risk communication as an integrative model. fournal of Health Communication 10, 1 (2005), 43-55. https://doi.org/10.1080/10810730590904571

[56] C. B. M. van Riel and J. M. T. Balmer. 1997. Corporate identity: The concept, its measurement and management. European fournal of Marketing 31, 5/6 (1997). https://doi.org/10.1108/eb060635

[57] T. Simon et al. 2014. Twitter in the cross fire-the use of social media in the Westgate mall terror attack in Kenya. Plos One 9, 8 (2014), 1-11. https://doi.org/10.1371/journal.pone.0104136

[58] Social media and the search for the Boston bombing suspects. 2013. Retrieved February 25, 2019, from https://www.cbsnews.com/news/ social-media-and-the-search-for-the-boston-bombing-suspects/.

[59] M. C. Stewart and B. G. Wilson. 2016. The dynamic role of social media during hurricane\# sandy: An introduction of the STREMII model to weather the storm of the crisis lifecycle. Computers in Human Behavior 54, (2016), 639-646.

[60] R. Thackeray et al. 2012. Adoption and use of social media among public health departments. BMC Public Health 12, 1 (2012). https: //doi.org/10.1186/1471-2458-12-242

[61] Transparency and Open Government. 2009. Retrieved July 28, 2019, from http://www.whitehouse.gov/the_press_office/ TransparencyandOpenGovernment.

[62] Uniform function | R Documentation. 2019. Retrieved September 26, 2019, from https://www.rdocumentation.org/packages/stats/ versions/3.6.1/topics/Uniform.

[63] J. Yoon et al. 2019. On the use of multimedia in Twitter health communication: Analysis of tweets regarding the Zika virus. Information Research 24, 2 (Jun. 2019).

[64] G. W. Yun et al. 2016. Social media and flu: Media Twitter accounts as agenda setters. International fournal of Medical Informatics 91 , (2016), 67-73. https://doi.org/10.1016/j.ijmedinf.2016.04.009

[65] S. M. Zavattaro and T. A. Bryer (Eds.). 2016. Social Media for Government: Theory and Practice. Routledge.

[66] X. Zhao et al. 2013. Impact of multimedia in Sina Weibo: Popularity and life span. In Semantic Web and Web Science. Springer, 55-65.

[67] Zika spraying kills millions of honeybees. 2016. Retrieved January 10, 2019, from http://www.cnn.com/2016/09/01/health/ zika-spraying-honeybees/index.html.

Received February 2019; revised October 2019; accepted November 2019

Digital Government: Research and Practice, Vol. 1, No. 2, Article 13. Publication date: April 2020. 